\title{
Research
}

Paper

\section{Repeated dose toxicity of deltamethrin in rats}

\author{
S. Manna', D. Bhattacharyya', T. K. Mandal'2, S. Das²
}

'Department of Pharmacology, University College of Medicine,

Calcutta University, Kolkata;

${ }^{2}$ Department of Pharmacology and Toxicology,

West Bengal University of Animal andFishery Sciences, Kolkata, India

Received: 5.5.2004

Revised: 9.9.2004

Accepted: 17.10.2004

Correspondence to:

T.K. Mandal

E-mail:

skmv2@rediffmail.com

\section{ABSTRACT}

Objective: To investigate the short-term toxicity of deltamethrin in rats. Materials and methods: Deltamethrin was dissolved in dimethyl sulphoxide and the oral $\mathrm{LD}_{50}$ was calculated to be $150 \mathrm{mg} / \mathrm{kg}$. Then groups of rats were given repeated daily oral dose $\left(1 / 10 L_{50}\right)$ of deltamethrin for 30 days. The animals were killed on $31^{\text {st }}$ day. Activities of various enzymes, cytochrome $\mathrm{P}_{450}$ and $\mathrm{b}_{5}$ contents in liver, hepatic antioxidant status, tissue residue concentration, haemogram and pathological changes were studied.

Results: Deltamethrin increased the serum aminotransaminase, alkaline phosphatase, lactate dehydrogenase activities and blood glucose level significantly. Deltamethrin decreased PCV and $\mathrm{Hb}$ level and the liver cytochrome $\mathrm{P}_{450}$ content significantly. Considerable amount of residues were present in different tissues. It increased malondialdehyde level, while decreased the activities of catalase, superoxide dismutase, reduced glutathione and glycogen levels in liver significantly. Mild to moderate histological alterations were observed in lungs, liver, stomach, kidney, testes and cerebellum.

Conclusion: Repeated dose toxicity studies of deltamethrin at $1 / 10 \mathrm{LD}_{50}$ altered the biochemical parameters; decrease cytochrome $\mathrm{P}_{450}$ content, antioxidant status, which correlated with histopathological changes with considerable amount in tissue residues.

KEY WORDS: Biochemical parameters; $\mathrm{LD}_{50}$; tissue residue.

\section{Introduction}

Deltamethrin is a synthetic pyrethroid with potent insecticidal property. The technical grade deltamethrin comprises of eight stereomeric esters (four cis and four trans isomers) of the dibromo analogue of chrysanthemic acid, 2,2dimethyl-3-cyclopropanecarboxylic acids. Deltamethrin is extensively used as an ectoparasiticide in animals and as insecticides in crop production and public health programme. ${ }^{[1]}$ Some of the toxic actions of deltamethrin have been reported earlier, ${ }^{[1]}$ but reports on tissue residue level and effects after repeated daily oral administration on cytochrome $\mathrm{P} 450$, cytochrome $b_{5}$, antioxidant status, blood biochemistry and histology of some tissues in rats are scarcely available. It has been recorded that the vehicle has a great influence on the $\mathrm{LD}_{50}$, probably by influencing absorption. The oral $\mathrm{LD}_{50}$ values of deltamethrin for rats were $52 \mathrm{mg} / \mathrm{kg}$ (in peanut oil) and $67 \mathrm{mg} / \mathrm{kg}$ (in polyethylene glycol 200). ${ }^{[1]}$ The dimethyl sulphoxide (DMSO) is not used in the commercial formulation, but it is one of the vehicles in which alpha-cypermethrin $(\alpha-$ $\mathrm{CP}$ ) is dissolved whenever it is used. The DMSO is used as a solvent for any organic compounds including $\alpha$-CP. Yet the $\mathrm{LD}_{50}$ of deltamethrin in DMSO (vehicle) has not been determined in rodents. Therefore, the present study was undertaken to determine the oral median lethal dose of deltamethrin dissolved in DMSO and to investigate the sub-acute toxicity (30 days) of deltamethrin in DMSO in rats.

\section{Materials and methods}

\section{Pesticide}

Deltamethrin (>99\% pure) was obtained from Gharda Chemicals Ltd., Bombay.

Animals and experimental design

Fifty-four adult Wistar rats of both sexes (equal sex ratio; weighing about $200 \pm 20 \mathrm{~g}$ ) were divided into nine equal groups (I-IX) each consisting six animals. All rats were kept under controlled conditions of temperature $\left(22 \pm 1{ }^{\circ} \mathrm{C}\right)$ and humidity $(60 \pm 5 \%)$. They were given pellet food (Amrut feeds Ltd., Pune, India) and drinking water ad libitum. A twelve-hour day and night cycle was maintained. The experimental protocol met the national guidelines on the proper care and use of animals in the laboratory research. The institutional animal ethics committee (IAEC) approved the experimental protocol. 
The animals were grouped as follows:

\begin{tabular}{llc}
\hline Groups & \multicolumn{1}{c}{ Treatment* } & Dose $(\mathrm{mg} / \mathrm{kg})$ \\
\hline Group-I & DMSO + deltamethrin & 100 \\
Group-II & DMSO + deltamethrin & 125 \\
Group-III & DMSO + deltamethrin & 150 \\
Group-IV & DMSO + deltamethrin & 175 \\
Group-V & DMSO + deltamethrin & 200 \\
Group-VI & DMSO + deltamethrin & 225 \\
Group-VII & DMSO (control for Groups I-VI) &
\end{tabular}

Short-term toxicity (30 days treatment)

Group-VIII DMSO + deltamethrin

Group-IX DMSO (control for Group-VIII)

*For all the groups, DMSO was adjusted to a final volume of $1 \mathrm{ml} / \mathrm{rat}$.

Groups I-VI were used for determination of $\mathrm{LD}_{50}$ of deltamethrin. Group VII served as control for Groups I-VI. The animals were fasted overnight and deltamethrin was administered orally after dissolving in DMSO $(1 \mathrm{ml})$ as stated above. The animals were observed for respiratory and CNS symptoms, behavioural changes and death and then $\mathrm{LD}_{50}$ was determined. ${ }^{[2]}$ Group VIII was used for repeated dose toxicity study. Group IX served as control for Group VIII. Deltamethrin was administered orally to the animals of Group VIII at 15$\mathrm{mg} / \mathrm{kg}$, body weight (b.w.) and Group IX animals were dosed equal volume of DMSO only ( $1 \mathrm{ml} /$ day) for 30 days. On the $31^{\text {st }}$ day, the animals were killed under halothane anesthesia by severing the neck vessels aseptically. Blood was collected in three sets of test tubes from each animal. Blood smears were prepared for differential leukocyte count. One set was kept under refrigeration $\left(4^{\circ} \mathrm{C}\right)$ for separation of serum and utilized for estimation of activities of aspartate transaminase (AST), ${ }^{[3]}$ alanine transaminase (ALT), ${ }^{[3]}$ lactate dehydrogenase $(\mathrm{LDH}){ }^{[4]}$ alkaline phosphatase (ALP) ${ }^{[5]}$ and total protein (TP) ${ }^{[6]}$ globulin and albumin (GLB, ALB). ${ }^{\left[{ }^{[7]}\right.}$ The blood of another set of test tubes having mixture of potassium oxalate and sodium fluoride as anticoagulant was used for estimation of glucose..$^{|8|}$ Blood in the third set of test tubes was heparinized and used for RBC and WBC counts and measuring PCV and hemoglobin level. All the absolute values were calculated according to Dacie and Lewis. ${ }^{[9]}$

Tissue

Portions of lungs, liver, stomach, kidney, stomach, testes and cerebellum were collected in $10 \%$ formalin solution for histopathology. One portion of liver was washed in physiological saline, homogenized and the homogenate was kept for estimation of catalase activity (CAT) ${ }^{, 10]}$ levels of reduced glutathione (GSH), ${ }^{[11]}$ malonyldialdehyde (MDA), ${ }^{112]}$ glycogen $^{[13]}$ and tissue protein. ${ }^{[14]}$ Another portion of liver was collected in ice-cold $1.15 \% \mathrm{KCl}$, homogenized within $10 \mathrm{~min}$, centrifuged, microsomal pellets separated and used for estimation of superoxide dismutase (SOD), ${ }^{[15]}$ cytochrome $\mathrm{P}_{450}$ and $\mathrm{b}_{5}{ }^{[16]}$ contents by DB-UV-Vis spectrophotometer.

Preparation of liver microsomal fraction

Animal was killed and the liver was perfused in situ with homogenizing buffer A (Tris-HCL + EDTA + BHT) by single pass injection through the portal vein and dissected out, placed in ice-cold KCl $(1.15 \%)$. All the subsequent steps in the prepa- ration of microsomal fraction were carried out at $0-4^{\circ} \mathrm{C}$. Then the liver was minced and mixed with four volumes of buffer A and homogenized in a mechanically driven Teflon glass homogenizer (Remi RQ $127 \mathrm{~A}$ ). The homogenate was centrifuged at $10000 \mathrm{~g}$ in an automatic high-speed cold centrifuge (Hitachi-SCR 20B) using the rotor RPR 20-2 for $30 \mathrm{~min}$. The supernatant was recentrifuged at $105000 \mathrm{~g}$ for $1 \mathrm{~h}$ in an automatic preparative ultracentrifuge (Hitachi 70 P-72, Japan) using rotor RP-65T to yield microsomal pellet. Microsomal pellet was suspended in buffer B (potassium pyrophosphate + EDTA + BHT) and homogenized with four passes of mechanically driven Teflon glass homogenizer (Remi RQ 127A) and again centrifuged at $104000 \mathrm{~g}$ for $1 \mathrm{~h}$. The supernatant fraction was decanted and the microsomal pellet was resuspended in a minimum volume of buffer $\mathrm{C}$ (Tris- $\mathrm{HCl}+$ EDTA + glycerol) and stored at $-20{ }^{\circ} \mathrm{C}$ till further use. The pellet was used for estimating SOD activity and cytochrome $\mathrm{P}_{450}$ and $\mathrm{b}_{5}$ levels.

Residue level

The tissue residue levels of $\alpha$-CP in brain, lungs, liver, heart, kidney and testes were estimated by the method of Marie et al., ${ }^{[17]}$ modified by Mandal $e t$ al.$^{[18]}$

Tissue sample preparation

Tissues $(2 \mathrm{~g})$ were extracted for $4 \mathrm{~min}$ with acetonitrile $(25 \mathrm{ml})$ and anhydrous sodium sulphate $(0.5 \mathrm{~g})$ using a homogenizer. The extract was filtered through anhydrous sodium sulphate $(0.5 \mathrm{~g})$ and the tissues were re-extracted twice with acetonitrile (first by 25 and then by $12 \mathrm{ml}$ ). The extract was clarified by centrifugation and filtered through anhydrous sodium sulphate. The combined acetonitrile extracts were concentrated to $20 \mathrm{ml}$ and partitioned with hexane $(2 \mathrm{x}$ $10 \mathrm{ml}$ ). The hexane phases were discarded and the acetonitrile phase was evaporated to dryness using a rotary vacuum evaporator at $40{ }^{\circ} \mathrm{C}$. The volume was finally made up to $5 \mathrm{ml}$ with acetone for GLC estimation.

\section{Calibration}

A stock solution of $1 \mathrm{mg} / \mathrm{l}$ of deltamethrin (analytical grade $>99 \%$ ) was prepared as an external standard. The retention time of deltamethrin was $5.25 \mathrm{~min}$. The data were recorded in a HP 3392A integrator.

\section{Apparatus}

A Hewlett Packard (USA) model 5890A gas chromatograph coupled with a 3392 A (HP) integrator and equipped with a $63 \mathrm{Ni}$ electron capture detector was used for analysis of deltamethrin.

\section{Histopathology}

Small pieces of lungs, liver, stomach, kidney and cerebellum were fixed in 10\% neutral buffered formalin and testis in Bouin's fluid. Sections of 3-5 mm thickness were cut and stained with hematoxylin and eosin (H\&E) for observation under light microscope.

\section{Statistical analysis}

All values are expressed as mean \pm SEM. Statistical analysis was done using SPSS 10.1. Statistical significance between two means was assessed by Student's ' $t$ ' test at $P<0.05$.

\section{Results}

Deltamethrin did not produce any gross effect at $100 \mathrm{mg} /$ $\mathrm{kg}$. However, at higher doses ranging from 125 to $225 \mathrm{mg} / \mathrm{kg}$, 
Table 1

Effects of deltamethrin on certain biochemical parameters in serum and blood of rats after daily oral administration at $15 \mathrm{mg} /$ $\mathbf{k g}$ for 30 days

\begin{tabular}{lcc}
\hline Parameters & Control & Deltamethrin \\
\hline Serum & & \\
ALP activity (IU/l) & $66.01 \pm 1.95$ & $135 \pm 5.10^{*}$ \\
AST activity (IU/l) & $58.21 \pm 1.98$ & $68.50 \pm 0.61^{*}$ \\
ALT activity (IU/l) & $10.89 \pm 0.85$ & $21.83 \pm 0.92^{*}$ \\
LDH activity (IU/l) & $47.45 \pm 2.12$ & $53.83 \pm 0.78^{*}$ \\
TP $(\mathrm{g} / \mathrm{dl})$ & $6.89 \pm 0.88$ & $6.80 \pm 0.08$ \\
ALB $(\mathrm{g} / \mathrm{dl})$ & $4.25 \pm 0.33$ & $4.05 \pm 0.19$ \\
GLB $(\mathrm{g} / \mathrm{dl})$ & $2.59 \pm 0.39$ & $2.75 \pm 0.14$ \\
Blood glucose (mmol/l) & $3.69 \pm 0.30$ & $6.14 \pm 0.34^{*}$ \\
Haemogram & & \\
RBC $\times 10^{12} / \mathrm{l}$ & $9.29 \pm 0.78$ & $7.45 \pm 0.38$ \\
WBC $\times 10^{9} / \mathrm{l}$ & $10.34 \pm 0.95$ & $9.13 \pm 1.92$ \\
Neutrophil $\times 10^{9} / \mathrm{l}$ & $2.98 \pm 0.09$ & $3.05 \pm 0.12$ \\
Eosinophil $\times 10^{9} / \mathrm{l}$ & $0.12 \pm 0.01$ & $0.06 \pm 0.00^{*}$ \\
Basophil $\times 10^{9} / \mathrm{l}$ & $0.03 \pm 0.00$ & $0.06 \pm 0.00^{*}$ \\
Lymphocyte $\times 10^{9} / \mathrm{l}$ & $6.42 \pm 0.08$ & $4.78 \pm 0.26^{*}$ \\
Monocyte $\times 10^{9} / \mathrm{l}$ & $0.41 \pm 0.03$ & $0.20 \pm 0.02^{*}$ \\
PCV & $0.37 \pm 0.007$ & $0.31 \pm 0.001^{*}$ \\
Hemoglobin $(\mathrm{g} / \mathrm{l})$ & $99.5 \pm 0.05$ & $85.0 \pm 7.3^{*}$ \\
\hline
\end{tabular}

Values are mean \pm SEM, $n=6$ in each group. ${ }^{*} P<0.05$ in comparison with control.

it produced signs of CNS stimulation followed by prolonged depression. Initially the intoxicated animals exhibited chewing, licking and salivation, which was followed by CNS depression. A variable sequence of motor symptoms developed that involved occasional pawing, or burrowing, coarse whole body tremor associated with movement, gradual development of hind limb extensor tone. Finally, choreoathetosis (sinuous writhing) developed and the animals exhibited slow twisting or writhing movement of neck and tail. Violently twisting movements sometimes lifted the body from the floor in severely affected animals, which were cases of severe athetosis. At the terminal stage, animals showed laboured breathing, gasping and death. The acute oral $\mathrm{LD}_{50}$ value of deltamethrin was calculated as $150 \mathrm{mg} / \mathrm{kg}$ body weights.

Biochemical and hematological profile

Effect of deltamethrin on certain blood and liver biochemical and antioxidants parameters are summarized in Tables 1 and 2, respectively. Deltamethrin significantly ( $P$ $<0.05)$ increased the activities of serum AST, ALT, ALP and LDH while the liver cytochrome $\mathrm{P}_{450}$ content and activities of CAT, SOD and GSH level were decreased and MDA level was increased significantly $(P<0.05)$ without any significant alteration of cytochrome $b_{5}$ content in liver. Blood glucose level was significantly $(P<0.05)$ increased and liver glycogen was significantly $(P<0.05)$ decreased. Serum ALB, GLB and total protein levels were not altered significantly. Deltamethrin decreased PCV, Hb level and counts of lymphocyte, monocyte and eosinophil, whereas basophil count was increased significantly (Table 1).

Tissue residue

The tissue residual concentration of deltamethrin following
Table 2

Effects of deltamethrin on certain biochemical parameters in liver of rats after daily oral administration at $15 \mathrm{mg} / \mathrm{kg}$ for 30 days

\begin{tabular}{lcc}
\hline Parameters & Control & $\begin{array}{c}\text { Deltamethrin } \\
\text { treated } \\
\text { (30 days) }\end{array}$ \\
\hline CAT activity (U/mg protein) & $0.32 \pm 0.03$ & $0.07 \pm 0.01^{*}$ \\
SOD (U/mg protein) & $0.42 \pm 0.03$ & $0.13 \pm 0.02^{*}$ \\
MDA (nmol/mg protein) & $0.19 \pm 0.02$ & $2.47 \pm 0.16^{*}$ \\
GSH ( $\mu \mathrm{mol} / \mathrm{mg}$ protein) & $1.61 \pm 0.06$ & $1.49 \pm 0.02^{*}$ \\
Glycogen (mg \%) & $8.12 \pm 0.46$ & $5.74 \pm 0.35^{*}$ \\
$\mathrm{P}_{450}(\mathrm{nmol} / \mathrm{mg}$ microsomal protein) & $2.38 \pm 0.05$ & $1.71 \pm 0.09^{*}$ \\
$\mathrm{~b}_{5}(\mathrm{nmol} / \mathrm{mg}$ microsomal protein) & $1.32 \pm 0.08$ & $1.50 \pm 0.15$ \\
\hline
\end{tabular}

Values are mean \pm SEM, $n=6$ in each group. ${ }^{\star} P<0.05$ in comparison with control.

repeated oral administration for 30 days were $0.92 \pm 0.01$, $0.74 \pm 0.05, \quad 0.10 \pm 0.01,0.09 \pm 0.01, \quad 3.00 \pm 0.12$ and $0.15 \pm 0.02 \mathrm{ppm}$ in liver, brain, testis, kidney, lungs and heart, respectively. The concentration of deltamethrin was maximum in the lungs.

Gross pathology

At post-mortem, rats showed bloated stomach with severe hemorrhages in both stomach and intestine. Hemorrhages were also seen in lungs. No gross changes were discernible in other visceral organs.

Histopathology

Deltamethrin produced congestion and emphysema in lungs (Fig. 1). Congestion and fatty changes were found in liver (Fig. 2). In stomach, it produced desquamation and necrosis of the epithelium. Kidneys showed congestion of the blood vessels (Fig. 3). The section of testis showed edematous fluid accumulation between the tubules and vacuole formation within the tubules (Fig. 4). Congestion and hemorrhages were also seen in intracerebellar vessels of the cerebellum (Fig. 5).

\section{Discussion}

The motor signs, following deltamethrin administration is strongly suggestive of central nervous system involvement. The acute oral $\mathrm{LD}_{50}$ value of deltamethrin in DMSO was found to be $150 \mathrm{mg} / \mathrm{kg}$, which is higher than the $\mathrm{LD}_{50}$ values of deltamethrin determined using other vehicles like peanut oil. This suggests that the vehicle DMSO reduced the toxicity of deltamethrin in rats. Activities of SOD and CAT and GSH and MDA levels in the liver reflect the oxidative status and the serum enzymes like AST, ALT, ALP represent the functional status of the liver. ${ }^{[19]}$ Increase of transaminase activity along with the decreased of content of free radical $\left(0_{2}-\right)$ scavengers are probably the consequence of deltamethrin induced pathological changes in liver and other visceral organs. Increased catecholamine leve ${ }^{[20]}$ causes glycogenolysis and this may be a reason for significant decrease in liver glycogen leading to hyperglycemia. Like the present findings, prolonged oral administration of cypermethrin and fenvalerate produced leucopenia and lymphocytopenia in rats. ${ }^{[1]}$ The decreased activities of CAT, SOD and GSH level and increased MDA level in liver as well as increased serum AST, ALT, ALP activities 
Figure 1. Photomicrograph of rat lungs showing congestion (C) and emphysema $(E)$ of alveoli after consecutive daily oral administration of deltamethrin at $15 \mathrm{mg} / \mathrm{kg}$ for 30 days (H\&E, 100x)

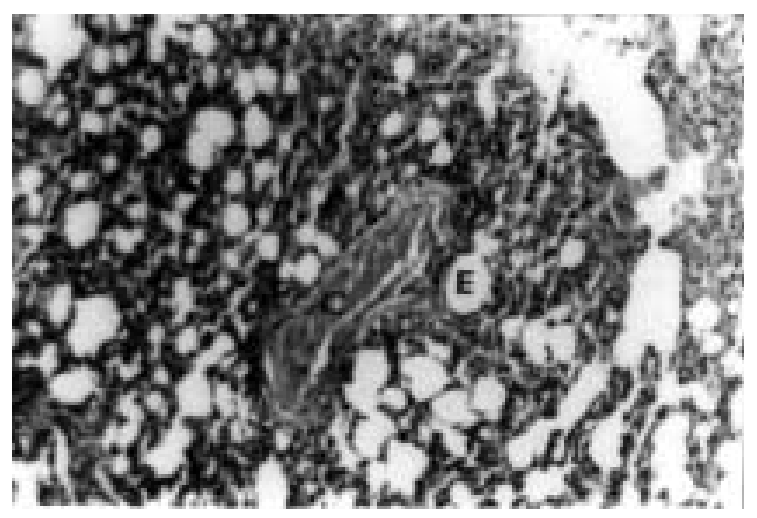

Figure 3. Photomicrograph of rat kidney showing congestion $(R)$ of the blood vessels after consecutive daily oral administration of deltamethrin at $15 \mathrm{mg} / \mathrm{kg}$ for 30 days (H\&E, 100x)

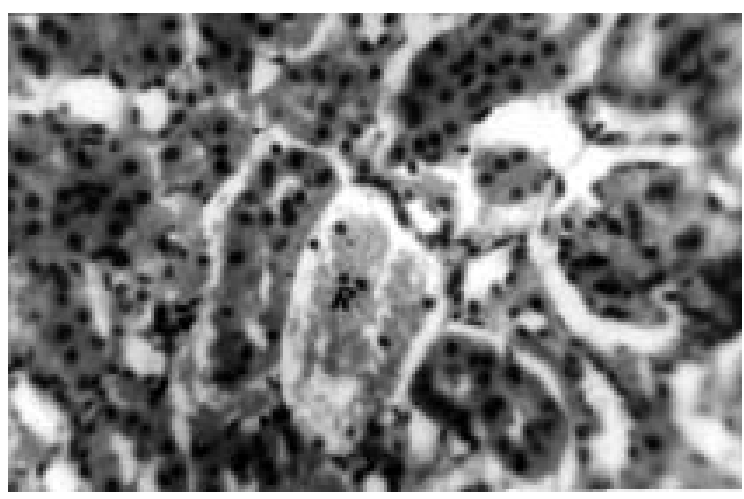

suggest that deltamethrin causes hepatic damage. The pathogenesis may be through free radical $\left(0_{2}-\right)$ formation. Deltamethrin undergoes metabolism in the liver via hydrolytic ester cleavage and oxidative pathways by the cytochrome $\mathrm{P}_{450}$ system. ${ }^{[22]}$ This may cause decreased content of $\mathrm{P}_{450}$ in liver (Table 2). It may results in oxidative stress leading to depletion of activities of CAT, SOD and levels of GSH and glycogen and increased level of MDA. These results may cause hepatic degeneration and necrosis. Alfa-one $(\alpha-1)$ an antitrypsin, normally present in serum, tissue fluids and macrophages is a major inhibitor of proteases (particularly elastase) secreted by neutrophils during inflammation and results in the degradation of elastin that introduce to formation of emphysema. High concentration of deltamethrin in lungs may have caused inflammation leading to progressive emphysema in the present study. In testes, vacuole formation and oedematus fluid accumulation were observed, which may cause testicular degeneration due to the presence of deltamethrin. The present status of antioxidants and status of biochemical changes correlated with histopathological changes of tissues,
Figure 2. Photomicrograph of rat liver showing fatty changes $(F)$ and congestion (C) of the blood vessels after consecutive daily oral administration of deltamethrin at $15 \mathrm{mg} / \mathrm{kg}$ for 30 days (H\&E, 100x)

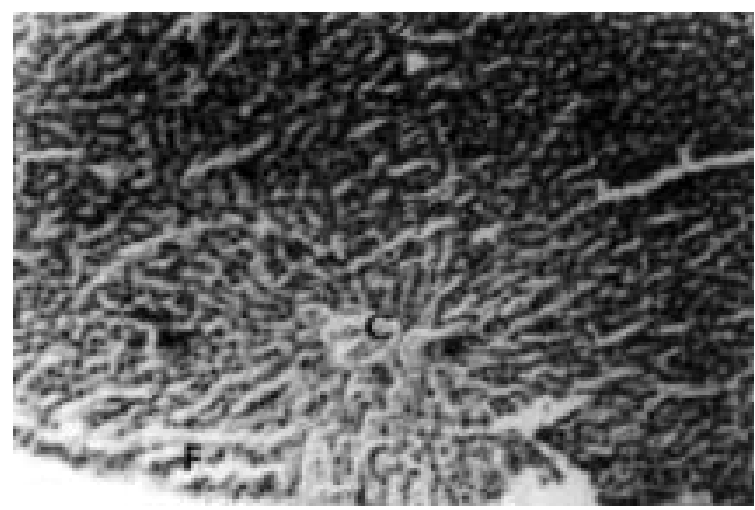

Figure 4. Photomicrograph of rat testes showing edematous fluid (F) accumulation between the tubules and vacuole $(\star)$ formation within the tubule after consecutive daily oral administration of deltamethrin at $15 \mathrm{mg} / \mathrm{kg}$ for 30 days (H\&E, 100x)

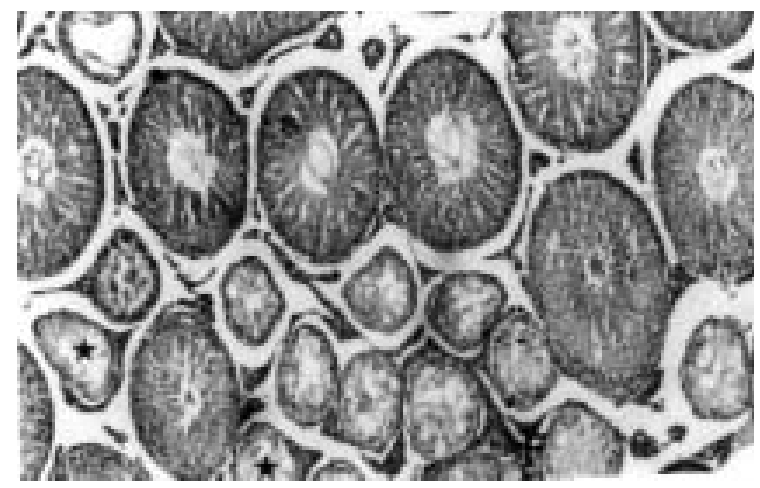

Figure 5. Photomicrograph of rat cerebellum showing congestion (C) of the blood vessels tubule after consecutive daily oral administration of deltamethrin at $15 \mathrm{mg} / \mathrm{kg}$ for 30 days (H\&E, 100x)

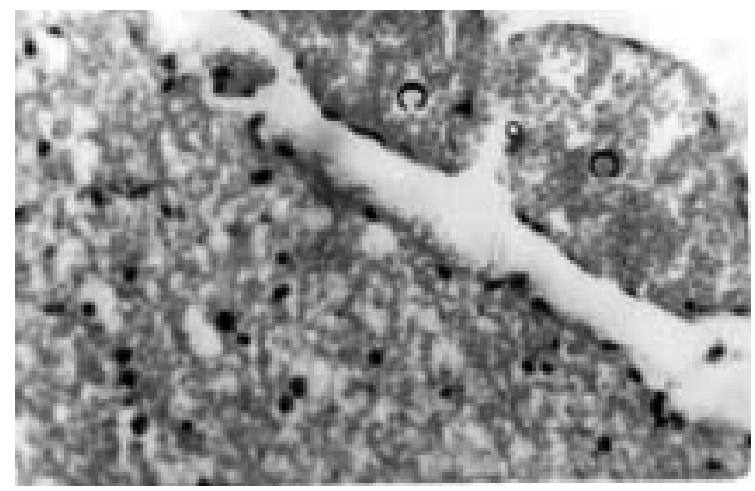


which corroborated with the findings of Giray. ${ }^{[22]}$ In conclusion repeated short-term toxicity at $1 / 10 \mathrm{LD}_{50}$ dose for 30 days decreased antioxidant status as well as increased the transaminase activity resulting in damage to important organs.

\section{Acknowledgments}

We acknowledge Prof. A. Chowdhury and Dr. A. Bhattacharya, Pesticide Residual Laboratory, Department of Agricultural Chemicals, Bidhan Chandra Krishi Viswa Vidyalaya, Nadia, West Bengal for providing GLC-ECD for tissue residual analysis and M/S. Gharda Chemical Ltd., Mumbai, India for gifting us analytical grade deltamethrin.

\section{References}

1. World Health Organization. Environmental Health Criteria-97. International programme on chemical safety. In: Deltamethrin, Library cataloguing in publication data. Geneva: WHO; 1990.

2. Miller LC, Tainter ML. Graphical method for determination of $L D$. Proc Soc Exp Biol Med 1944; 57:261.

3. Reitman S, Frankel S. A colorimetric method for the determination of glutamic oxaloacetic and glutamic pyruvic transaminase. Am J Clin Pathol 1957;28:5663.

4. Bergmeyer HU, Bernt E, Hess B. Lactate dehydrogenase. In: Methods of Enzymatic Analysis. Bergmeyer HU, editor. London: Academic Press; 1974.

5. King EJ, Armstrong AR. In vitro determination of alkaline phosphatase, Canad. Med Ass J 1934; 31:376.

6. Doumas BT, Waston WA, Biggs AG. Albumin standard and the measurements of serum albumin with bromcresol greeen. Clin Chem Acta 1971;31:87-96.

7. Rodkey FL. Direct spectrophotometric determination of Albumin in Human serum. Clin Chem 1965;11:478-87.

8. Trinder P. In vitro enzymatic colorimetric method for the estimation of glucose in serum/plasma. Ann Clin Biochem 1969;6:24.

9. Dacie JY, Lewis SM. Practical hematology. $7^{\text {th }}$ ed. New York: Churchill Livingston; 1991.
10. Lick H. Catalase. In: Methods of Enzymatic Analysis. Bergemeuer HU, editor. $3^{\text {rd }}$ ed. Verlag Chemie; New York: Academic press; 1963. p. 885-8.

11. Griffith $\mathrm{OW}$. Determination of glutathione and glutathione disulphide using glutathione reductase and 2- vinylpyridine. Anal Biochem 1980; 106:207-12.

12. Placer ZA, Cushmanm LL, Jhonson BC. Estimation of product of lipid peroxidation (malonyl dialdehyde) in biochemical system. Anal Biochem 1966;16:359-64.

13. Montgomery R. Determination of glycogen. Arch Biochem Biophys 1957;67:37886.

14. Lowry $\mathrm{OH}$, Rosenbrough NJ, Farr AL, Randall, RJ. Protein measurement with folin-phenol reagent. J Biol Chem 1951;193:265-75.

15. Misra HP, Fridovich I. The role of superoxide anion in the antioxidation of epinephrine and a simple assay for superoxide Dismutase. J Biol Chem 1972; 247:3170-5

16. Omura T, Sato R. The carbon monoxide binding pigment of liver microsomes evidence for its hemoprotein nature. J Biol Chem 1964;239:2370-8.

17. Marie AE, Ruzo LO, Casida JE. Analysis and persistence of permethrin, cypermethrin, deltamethrin and fenvalerate in the fat and brain of treated rats. J Agric Food Chem 1982;30:558-62.

18. Mandal TK, Bhattacharyya A, Chakraborty AK, Basak DK. Disposition kinetics, cytotoxicity and residues of fenvalerate in tissue following oral administration to goats. Pesticide Science 1992; 35:201-7.

19. Cremer JE, Seville MP. Comparative effects of two pyrethroids, deltamethrin and cismethrin on plasma catecholamines and on blood glucose and lactate. Toxicol Appl Pharmacol 1982;66:124-33.

20. Varshneya C, Sing T, Sharma LD, Bagha HS, Garg SK. Immunotoxic response of cypermethrin, a synthetic pyrethroid insecticides in rats. Indian J Physiol Pharmacol 1992;36:123-6.

21. Floodstrom S, Warngard L, Lijunquist S, Ahlborg UG. Inhibition of metabolic cooperation in vitro and enhancement enzyme altered foci incidence in rat liver by the pyrethroid insecticide fenvalerate. Arch Toxicol 1988;61:218-23.

22. Giray B, Gurbay A, Hinealm F. Cypermethrin induced oxidative stress in rat brain and liver is prevented by Vit-E or allopurinol. Toxicol Lett 2001;118:139-46.

\section{FUNDAMENTALS OF EXPERIMENTAL PHARMACOLOGY}

\section{by}

\section{M.N. Ghosh}

The third edition of Prof. M.N. Ghosh's book "Fundamentals of Experimental Pharmacology" has been published on 17-03-2005. In this edition the chapters on Receptors have been extensively revised and updated, a few more evaluation techniques have been added, a small introductory chapter on Nitric oxide has been incorporated. A number of new drugs with their dose and concentration have been added in the respective sections that serve as useful reference for the research workers. The analysis of variance (ANOVA) has found a place in the chapter on the Statistical Methods.

The hard bound copy of the book consisting of 268 pages is priced Rs. $250 /=$ and is available with: M/S Hilton \& Company, 109, College Street, Kolkata-700 012; Telefax: 91-33-2237-1568; E-mail: hilton1890@yahoo.co.in 